\title{
Pre-treatment techniques in Reverse Osmosis Membrane system for well water to improve performance and reduce scale formation
}

\author{
Pratapsinh S Jadhav, Kailas P Dandge, Sanjay Gade
}

\begin{abstract}
In recent years, industrialization and human activities is affecting the ground water in many ways due to the over exploitation, discharge of hazardous constituents, material leading to the pollution and contamination of ground water. This has become a matter of concern to the ground water quality and quantity. The quality of ground water is contaminated and not suitable for human consumption. The water consumption rate is increasing along with the population growth. The treatment of ground water is a necessity in view of the increased demand and also to ensure safe and good quality water is being available. Reverse Osmosis (RO) membrane is one of the methods for treatment of ground water to remove the dissolved solids and other impurities to make the water suitable for use. However the RO membranes are susceptible to scaling and fouling which ultimately reduces the life and recovery of water. This paper is related to the removal of calcium carbonate scaling from well water to enhance the water recovery rate and reduce the scaling on the membranes.
\end{abstract}

Index Terms-Pre-treatment to RO, RO Membrane, Membrane scaling, well water treatment.

\section{INTRODUCTION}

Water is one of the important constituent for the existence of life on the earth. The global population is increasing and requirement of fresh water is also increasing. The fresh water scarcity is a growing as only $1 \%$ of earth's water is fresh water available for human consumption [6]. The US geological survey found that $96.5 \%$ of earth's water is located in seas and oceans and $1.7 \%$ of earth's water is located in the ice caps. The remaining percentage is made up of brackish water, slightly salty water found as surface water in estuaries and as groundwater in salty aquifers [4]. The fresh water availability and demand is at the top of the international agenda of critical problems, at least as firmly as climate change. India as a country has $16 \%$ of the world's population and $4 \%$ of its fresh water resources [7].

Manuscript revised June 10, 2019 and published on July 10, 2019 Pratapsinh S Jadhav, M.tech Student, SEES, Kavayitri Bahinabai Chaudhari North Maharashtra University, Jalgaon, India-425001, Emailps_jadhav123@yahoo.com

Kailas $P$ Dandge, Assistant Professor, SEES, Kavayitri Bahinabai Chaudhari North Maharashtra University, Jalgaon, India-425001 Email kpdandge@nmu.ac.in

Sanjay Gade, Director-Innovative Enviro, Mumbai-400705, Email: sanjay@innovativenviro.com
The industrial growth and other developmental activities in recent times are increasing the pollution load and deteriorating water quality. The water demand is increasing fast due to increase in the demand of water for irrigation, industrialization, and population growth and improving life standards [3].

In India, almost 70 per cent of its surface water resources and groundwater are polluted and contaminated by biological toxic, organic and inorganic pollutants. Growing demand for water in agriculture, industrial and domestic sectors has brought problems of overexploitation of the groundwater resource resulting in continuous decline in groundwater levels. In Maharashtra, out of 353 assets of groundwater, 19 are semi critical, 1 is critical and 9 are over exploited. The effects of water pollution are not only devastating to humans but also to flora and fauna. With a growing economy and changing lifestyles the pressure on already strained water resources is increasing [5].

In view of the increased demand and scarcity of water, the extraction of water from wells has increased in the areas where no or limited surface water source exists and inadequate supply of water by municipal corporations. However in most of the cases the extracted water quality is contaminated and the quality parameters are not suitable for drinking water, agricultural and industrial requirements.

Typically, water extracted from a bore well is high in sodium chloride. Sodium retains water in the soil, leading to arid conditions, and consequently affecting the absorption of nutrients by the plants. Chlorides are highly soluble in water and can be absorbed by plants affecting the growth. The common constituents in well water include chlorides, calcium, sodium, bicarbonate and sulphate ions [1].

Reverse osmosis is one of the efficient and economically suitable alternatives for water treatment to reduce levels of total dissolved salts and other impurities. RO is used in many industries to produce purified water for drinking, boilers, food and beverage, pharmaceuticals, seawater desalination, and many other applications.

However, a key challenge in operating the RO membranes is avoiding scaling and fouling of the membranes. This affects and reduces the recovery rate and life of the membranes.

Trouble with the performance of an RO system leads to one of the following:

- Loss of normalized permeate flow rate resulting increase in the feed pressure in order to maintain the desired permeate output.

- Increase in normalized solute passage typically associated with an increase in permeates total dissolved solids. 
- The difference between feed pressure and concentrate pressure resulting increase in pressure drop.

Most of the RO plants are operated at lower recovery rates due to insufficient pre-treatment to the RO feed water. The spiral wound membranes structure lacks the provision of back pulsing with water or air agitation to scour its surface and remove solids. Since accumulated material cannot be removed from the membrane surface systems, they are high possibilities of fouling and scaling resulting in loss of production capacity. To avoid troubles with the operations, pre-treatment to the feed water is important when working with reverse osmosis.

\section{STUdy AREA}

This study involves well water scaling tendency due to calcium carbonate saturation on the membranes and improve the percentage recovery and life of the membranes by providing required pre-treatment. Physicochemical characteristics of groundwater are taken from the E-Journal of Chemistry for Amalner town [2].

TABle 1: FeEd WATER QuAlity [2]

\begin{tabular}{|c|c|c|c|}
\hline S. No & Parameters & Unit & Values \\
\hline 1 & $\mathrm{pH}$ & & 7.1 \\
\hline 2 & Electrical Conductivity & $\mu \mathrm{S} / \mathrm{cm}$ & 2287 \\
\hline 3 & Total Dissolved Solids & $\mathrm{mg} / \mathrm{l}$ & 1760 \\
\hline 4 & Turbidity & $\mathrm{mg} / 1$ & 0.1 \\
\hline 5 & Dissolved Oxygen & $\mathrm{mg} / \mathrm{l}$ & 2.2 \\
\hline 6 & Total Alkalinity & $\mathrm{mg} / 1$ & 604 \\
\hline 7 & Total Hardness & $\mathrm{mg} / \mathrm{l}$ & 870 \\
\hline 8 & Calcium $\left(\mathrm{Ca}^{2+}\right)$ & $\mathrm{mg} / 1$ & 114.6 \\
\hline 9 & Magnesium $\left(\mathrm{Mg}^{2+}\right)$ & $\mathrm{mg} / 1$ & 142.3 \\
\hline 10 & Sodium $\left(\mathrm{Na}^{+}\right)$ & $\mathrm{mg} / \mathrm{l}$ & 233.2 \\
\hline 11 & Potassium $\left(\mathrm{K}^{+}\right)$ & $\mathrm{mg} / \mathrm{l}$ & 1.005 \\
\hline 12 & Chlorides $\left(\mathrm{Cl}^{-}\right)$ & $\mathrm{mg} / \mathrm{l}$ & 447.9 \\
\hline 13 & Nitrates $\left(\mathrm{NO}_{3}^{-}\right)$ & $\mathrm{mg} / \mathrm{l}$ & 0.765 \\
\hline 14 & Sulphates $\left(\mathrm{SO}_{4}{ }^{2-}\right)$ & $\mathrm{mg} / \mathrm{l}$ & 62.92 \\
\hline 15 & Phosphates $\left(\mathrm{PO}_{4}{ }^{3-}\right)$ & $\mathrm{mg} / \mathrm{l}$ & 0.155 \\
\hline
\end{tabular}

\section{Methodology:}

Secondary information on ground water quality for Amalner town was collected. Performance study using membranes simulation software's provided by different manufacturers
(GE, Toray, Hydranautics \& DOW) were done. The TDS removal efficiencies, membrane scaling tendency and recovery percentage using the RO membrane manufacturer's projections software were used and the observations were recorded.

A pre-treatment to the feed water using hydrochloric acid and water softener to enhance the recovery and reduce scaling to enhance the life of membranes was considered and the results were observed and recorded from the RO projections.

The Langelier Saturation index (LSI) is probably the most widely used indicator for RO membrane scaling related to calcium carbonates scale formation and growth.

TABLE 2: LSI INTERPRETATION

\begin{tabular}{|l|l|l|l|}
\hline Test & Value & Interpretation & Reference \\
\hline LSI & 2 & Scale Formation & $\begin{array}{l}\text { Langelier } \\
1936\end{array}$ \\
\cline { 2 - 4 } & 0.5 & $\begin{array}{l}\text { Scale forming and } \\
\text { corrosive }\end{array}$ & $\begin{array}{l}\text { ASTM } \\
\text { D3739-94 } \\
\text { (Internationa }\end{array}$ \\
\cline { 2 - 3 } & 0 & $\begin{array}{l}\text { Balanced but pitting } \\
\text { corrosive possible }\end{array}$ & 2003) \\
\cline { 2 - 3 } & -0.5 & $\begin{array}{l}\text { Slightly corrosive } \\
\text { but non-scaling } \\
\text { forming }\end{array}$ & \\
\hline & -2 & Serious Corrosive & \\
\cline { 2 - 3 } & & \multicolumn{2}{|l|}{} \\
\hline
\end{tabular}

\section{RESUltS:}

The feed water quality as indicated in table 1 above was used to run the projections. A feed flow rate of $10 \mathrm{~m}^{3} / \mathrm{hr}$ was considered for the study. Three different scenarios were considered and the results observations were recorded as below.

\section{Case 1: Without any Pre-Treatment to the Feed water}

Simulation was carried at $50 \%, 60 \%$ and $70 \%$ recovery rates without any pre-treatment dosing and the membrane performance with respect to the TDS removal, recovery rate and Langelier Saturation index (LSI) were recorded.

A graphical presentation of the LSI value, TDS removal percentage at different water recovery rates is shown in figure 1 below.

The values indicate that as the recovery rate increases the TDS removal efficiencies increases. However the LSI values of the concentrate stream also increases as the recovery rate increases indicating high tendency of $\mathrm{CaCo} 3$ saturation. This shall lead to increase in scaling potential and eventually decrease in the membrane life. 


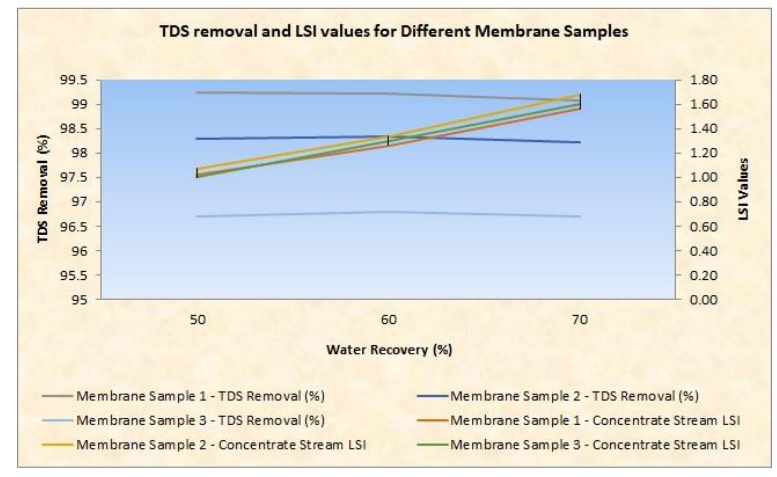

Figure 1: Concentrate Stream LSI Values \& TDS Removal (\%) at Different Water Recovery Rate for Different Membranes

\section{Case 2: Pre-Treatment with Hydrochloric Acid to the Feed Water:}

Simulation was carried at $50 \%, 60 \%, 70 \%, 75 \%$ and $80 \%$ recovery rates using hydrochloric acid as pre-treatment to reduce calcium carbonate scaling. Four Brackish water RO membranes from different manufacturers were selected and the RO projections were run. The membrane performance with respect to the TDS removal, recovery rate and Langelier Saturation index (LSI) were observed and recorded.

\section{Membrane -1}

Hydrochloric acid used as pre-treatment. Trial was done at $\mathrm{pH} 5.75 \& 6.0 \mathrm{pH}$ to increase the water recovery from $50 \%$ to $75 \%$.

A graphical presentation of the LSI value, TDS removal percentage at different water recovery rates after pre-treatment with hydrochloric acid is shown in figure 2 below. This has reduced the $\mathrm{CaCo} 3$ saturation in the concentrate stream. Also increase in the recovery rates as high as $75 \%$ by selecting optimum acid dosing was observed. The TDS removal efficiency remains almost similar ranging from 98.1 to $98.3 \%$.

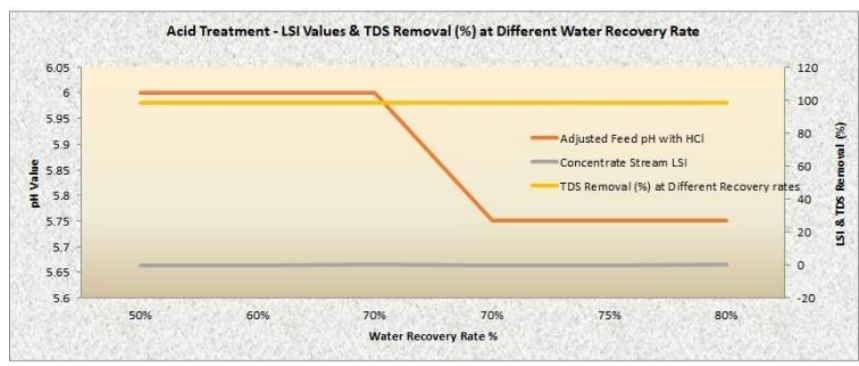

Figure 2: Concentrate Stream LSI Values \& TDS Removal (\%) at Different Water Recovery Rate for Membrane -1

\section{Membrane -2}

Trial was done at $\mathrm{pH} 5.75 \& 6.0 \mathrm{pH}$ to increase the water recovery from $60 \%$ to $80 \%$.

A graphical presentation of the LSI value, TDS removal percentage at different water recovery rates after pre-treatment with hydrochloric acid is shown in figure 3 below. This has reduced the $\mathrm{CaCo} 3$ saturation in the concentrate stream. Also increase in the water recovery rates as high as $75 \%$ by selecting optimum acid dosing was observed. The TDS removal efficiency ranges from minimum 98.79 to maximum $99.26 \%$.

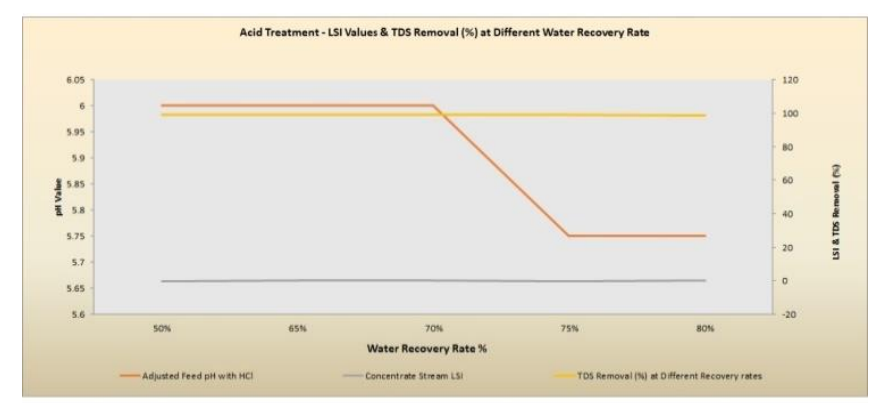

Figure 3: Concentrate Stream LSI Values \& TDS Removal (\%) at Different Water Recovery Rate for Membrane - 2

\section{Membrane -3}

Trial was done at $\mathrm{pH} 5.5 \& 6.0 \mathrm{pH}$ to increase the water recovery from $60 \%$ to $80 \%$.

A graphical presentation of the LSI value, TDS removal percentage at different water recovery rates after pre-treatment with hydrochloric acid is shown in figure 4 below. This has reduced the $\mathrm{CaCo} 3$ saturation in the concentrate stream. Also increase in the water recovery rates as high as $80 \%$ by selecting optimum acid dosing was observed. The TDS removal efficiency ranges from minimum 97.55 to maximum $98.53 \%$.

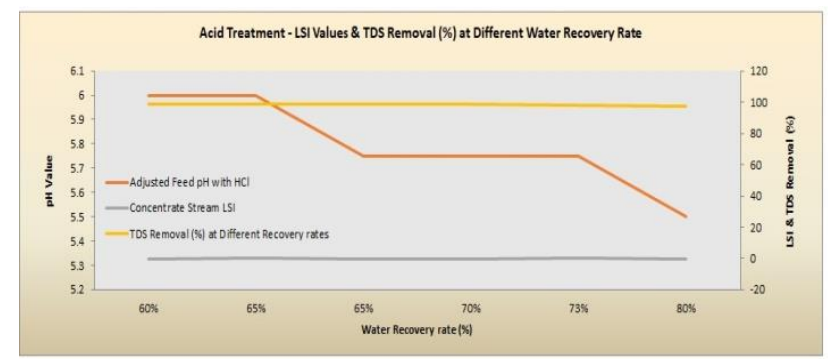

Figure 4: Concentrate Stream LSI Values \& TDS Removal (\%) at Different Water Recovery Rate for Membrane -3

\section{Membrane - 4}

Trial was done at $\mathrm{pH} 5.5 \& 6.0 \mathrm{pH}$ to increase the water recovery from $60 \%$ to $80 \%$. A graphical presentation of the LSI value, TDS removal percentage at different water recovery rates after pre-treatment with hydrochloric acid is shown in figure 5 below. This has reduced the $\mathrm{CaCo} 3$ saturation in the concentrate stream. Also increase in the water recovery rates as high as $80 \%$ by selecting optimum acid dosing was observed. The TDS removal efficiency ranges from 94.92 to $96.46 \%$. 


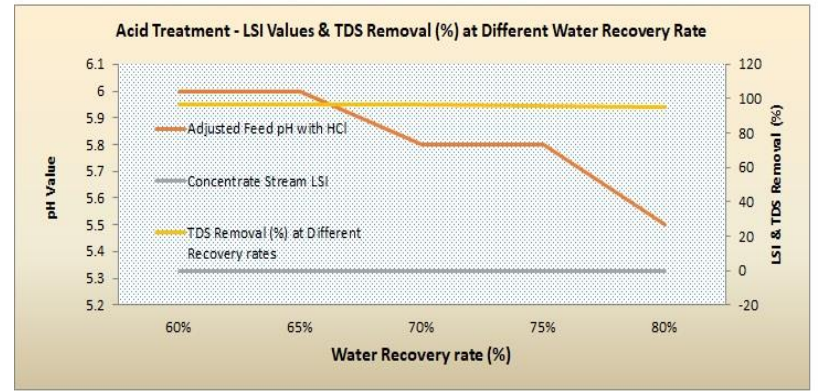

Figure 5: Concentrate Stream LSI Values \& TDS Removal (\%) at Different Water Recovery Rate for Membrane - 4

\section{Case 3: Pre-Treatment with Sodium Based Softener to the Feed Water:}

Trial was done with water softener on two types of RO membranes to increase the water recovery. A graphical presentation of the LSI value, TDS removal percentage after pre-treatment with softener is shown in figure 6 below.

Sodium based ion exchange resins used as pre-treatment replaces the calcium ions with sodium ions. This has resulted in negative LSI values. As a result the $\mathrm{CaCo} 3$ saturation in the concentrate stream is reduced.

Membrane -1 showed increase in the recovery rates as high as $80 \%$ with hardness levels of 5 ppm and $85 \%$ with hardness levels of $2 \mathrm{ppm}$. However the TDS removal rates observed are $97.48 \%$ \& $97.15 \%$ at $80 \%$ and $85 \%$ water recovery rates which are slightly lower than the acid treatment recovery rates.

Membrane -2 showed increase in the recovery rates as high as $85 \%$ with hardness levels of 5 ppm and $90 \%$ with hardness levels of $2 \mathrm{ppm}$. However the TDS removal rates observed are $94.85 \% \& 91.88 \%$ at $85 \%$ and $90 \%$ water recovery rates which are lower than the acid treatment recovery rates.

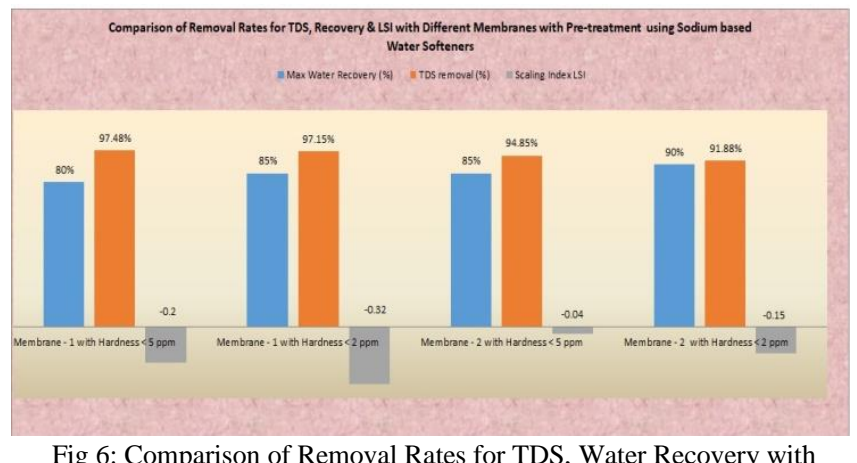

Fig 6: Comparison of Removal Rates for TDS, Water Recovery with Different Membranes with Pre-treatment using Water Softeners

\section{Conclusion}

From the analysis carried it has been concluded that a proper pre-treatment if applied will definitely be useful to increase recovery as well as life of the membranes.

It is observed that that the bore well water sample of Amalner town was having TDS of $1760 \mathrm{ppm}$ and Total hardness of $870 \mathrm{ppm}$. The water has the calcium carbonate scaling potential which shall affect the life of the membrane and the water recovery rate. From the analysis done using simulations with Hydrochloric acid and sodium based ion exchange water softener we can summarize the following findings:

1. RO membranes operated without pre-treatment to the feed water shall lead to scaling and fouling and reduce the life of the membranes and operate at low water recovery rate.

2. Providing pre-treatment such as Hydrochloric acid can enhance the water recovery rates as high as $75 \%$ $-80 \%$.

3. Pre-treatment with sodium based ion exchange softeners in place of Hydrochloric acid show better results and can enhance the recovery to $85 \%-90 \%$.

4. Pre-treatment reduces the calcium carbonate scaling on the membranes and the TDS removal is achieved more than $90 \%$.

5. Scaling of the membranes is reduced, which ultimately increases life of the membranes.

6. Increasing the water recovery ultimately decreases the reject water quantity for disposal to the environment.

\section{REFERENCES}

[1] D. Dohare, S Deshpande, A.Kotiya, (2014), Analysis of Ground Water Quality Parameters. A Review by Devendra Dohare, Shriram Deshpande and Atul Kotiya

[2] Dr. V.Patil \& Dr. P Patil (2009), Physicochemical Analysis of Selected Groundwater Samples of Amalner Town in Jalgaon District, North Maharashtra University Jalgaon.

[3] Hardikkumar V. Shrimali, A Brief Review on Reverse Osmosis Technology" International Journal of Research in Advent Technology, Vol.3, No.5, May 2015 E-ISSN: 2321-9637

[4] L. F. Greenlee, D. F. Lawler, B. D. Freeman, B. Marrot, and P. Moulin, "Reverse osmosis desalination: water sources, technology, and today's challenges," Water Research, vol. 43, no. 9, pp. 2317-2348, 2009

[5] MPCB- Water Quality Status of Maharashtra 2015-16

[6] Pangarkar ${ }^{1}$, Sane $^{2} \&$ Guddad1 (2011), A review on Reverse Osmosis and Membrane Distillation for Desalination of Groundwater, ${ }^{1}$ Sir Visvesvaraya Institute of Technology, University of Pune, Nashik, ${ }^{2}$ National Chemical Laboratory, Pune

[7] T. Abraham and A. Luthra, "Socio-economic and technical assessment of photovoltaic powered membrane desalination processes for India," Desalination, vol. 268, no. 1-3, pp. 238-248, 20

\section{AUTHORS PROFILE}

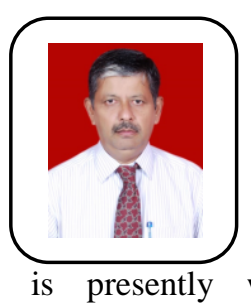

Mr. Pratapsinh S Jadhav, Email: ps_jadhav123@yahoo.com,

Mr. Pratapsinh $\mathrm{S}$ Jadhav is an environemntal professional with more than 24 years of experience in the field of water and wastewater treatment technologies. He is presently working with $\mathrm{M} / \mathrm{s}$ SFC Environmental Technologies, Mumbai as a General Manager. He has done his Masters in Environment Management from Shivaji University Kolhapur and presently pursuing M.Tech in Environment Science \& Technology from North Maharashtra University Jalgaon. He has been working on various treatment technologies in the field of water and wastewater treatment like Reverse Osmosis, Effluent treatment, Ultrafiltration, Membrane Bio Reactor (MBR) Sequential Batch reactor (SBR) etc. throughout his carrier and has experience in design, engineering and project management of 
the water projects. He is also a Life member of the Indian Water Works Association. He has earlier worked with companies like M/s Ion Exchange India Ltd. Mumbai, Tata Consulting Engineers Ltd. Mumbai, Jacobs Engineering Ltd Mumbai.

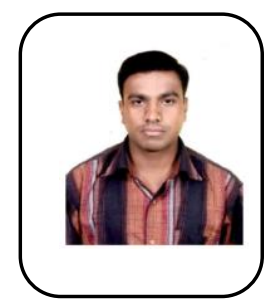

Mr. Kailas Pandurang Dandge,

E-mail: kpdandge@nmu.ac.in, kpdandge@gmail.com,

Mr. Kailas Pandurang Dandge is working as Assistant Professor in Department of Environmental Science, School of Environmental and Earth Sciences, Kavayitri Bahinabai Chaudhari North Maharashtra University, Jalgaon - 425001 (M. S.) India. Mr. Dandge has completed his M. Sc. NET (Environmental Science) and has more than 10 years of teaching experience. His area of expertise is Water and Wastewater Treatment, Environmental Management. Mr. Dandge was involved in research project titled

1. Effects of process factors on the efficiency of mixed aerobic culture for the de-colorization of Reactive Red Dye under funding by UGC Delhi

2. Remote Sensing and GIS Technology for mapping spatial variations of Water Quality Index in Erandol area, Jalgaon District, Maharashtra State under funding by DST-SERB, New Delhi

$\mathrm{He}$ is actively involved in research projects, attended various seminars and conferences and published around 7 research papers related to environment and water.

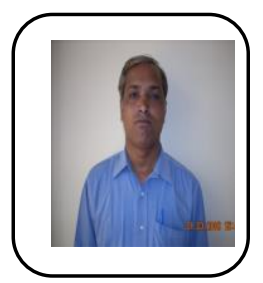

Mr. Sanjay Gade, E-mail: sanjay@innovativenviro.com,

Mr. Sanjay Gade is an environemntal professional with more than 24 years of experience in the field of water and wastewater treatment technologies. He is presently a Partner and Director of $\mathrm{M} / \mathrm{s}$ Innovative Enviro located in Navi-Mumbai dealing with projects related to water and wastewater in India and abroad. $\mathrm{He}$ has the experience from conceptulisation to commssioning of the water and wastewater projects. He has completed his Batchelors degree in Chemistry and has IT skills related to $\mathrm{C}, \mathrm{C}++$, Java, J2EE.

He has been working on various treatment technologies in the field of water and wastewater treatment like Reverse Osmosis, Effluent treatment, Ultrafiltration, Membrane Bio Reactor (MBR) etc. throughout his carrier and has experience in design, engineering and project management of the water projects. He has earlier worked with companies like Aireff Detox Ltd. Thane, Ion Exchange India Ltd. Mumbai, Africa Enviro Sytems Mumbai. 